\title{
Social Media Marketing Towards Consumer Buying Behavior: A Case in Panabo City
}

\author{
Jade Xuccheney N. Jacinto ${ }^{1}$, Joylyn S. Pintado ${ }^{2}$, Louie Jay M. Ibañez ${ }^{3}$, Ronel G. Dagohoy ${ }^{4}$, Mark Van M. Buladaco ${ }^{5}$ \\ ${ }^{123}$ Student, Bachelor of Science in Information Technology, Davao del Norte State College \\ ${ }^{4}$ Faculty, Institute of Leadership, Entrepreneurship and Good Governance, Davao del Norte State College \\ ${ }^{5}$ Dean, Institute of Computing, Davao del Norte State College
}

\begin{abstract}
Consumers are the kings of markets. No business enterprise can operate without the presence of the consumer, and with the advancement of technology, consumers tend to make countless decisions in purchasing with the use of social media. This study aims to evaluate the influence of social media marketing on consumer buying behavior, particularly among Panabo City citizens who mostly use social media websites to purchase products and services. The study utilizes a nonexperimental quantitative research approach, combining correlational and regression techniques. Convenience sampling and Slovin's formula was used to identify the 399 respondents. With the application of mean, frequency, Pearson $r$, and Regression Analysis, the result shows that there is a positive, moderate, and significant correlation between social media marketing and consumer buying behavior. Thus, it has been found out that among the indicators of social media marketing, all are predictors of consumer buying behavior. Furthermore, regression analysis results revealed that social media marketing significantly influences consumer buying behavior. Hence, consumers are influenced by process factors and external stimuli brought by social media marketing.
\end{abstract}

Keywords: Correlational Research, Social Media Marketing, Consumer Buying Behavior, Panabo City

\section{INTRODUCTION}

\section{A. Background of the Study}

Consumers are the kings of markets. No business enterprise can operate without the presence of the consumer. The analysis of customer behavior is focused on consumer buying behavior, with the customer playing the three distinct users, payer and buyer positions [1]. Consumer buying behavior refers to the behaviors of when, why, how, and where goods are purchased or not bought before buying a product or service by customers (both on and offline) [2]. In any field of business and services, consumer behavior is the most concentrated sector. Nowadays, discovering the changing needs and desires of consumers in today's world is the main deciding factor for every business. As cited by Peighambari and colleagues, the literature on consumer behavior is diverse and comprehensive as changes in culture, economics, and technology influence the way consumers act. These changes eventually lead to modified studies of consumer behavior from where, where, how, and why the subjects are studied [2]. Meanwhile, Ramirez postulates that the contemporary issues of consumer buying behavior are clearly evident and influenced by the 2007 economic downturn and the rising development of technology since 2008 [3]. Today, with the emergence of technology, the whole shopping experience has completely altered the marketing and customer purchasing behavior scenario.

The primary importance of consumer buying behavior lies in the fact that people can know how the consumer is going to behave, what are their impulses, needs, demands, wants, necessity, and lifestyle. Additionally, for marketers, it is most important so they can comprehend the consumer's desires. It helps to know what makes a customer purchase a product, and it increases marketers' revenue, segmentation, targeting, and forecasting. In order to release it to the market, it is necessary to determine the type of goods that customers want. With the advancement of technology, the marketer uses social media as advertising and even a medium of selling their services and products. Marketers reap the benefits of this and create a marketing strategy that could, in turn, help them gain more customers. It is very easy to use the social media environment and to reach customers because people nowadays use social media to communicate and interact with others. Social media marketing has provided companies with a new way of engaging with and improving customer buying behavior. These experiences help marketers assess the requirements of consumers and consider what their competition could look like. Social media marketing has also built new consumer behavior [4].

Asma and Misbah have presented a linked relationship between social media marketing and consumer buying behavior, and it shows that SMM is an effective marketing tool that affects the perception of customers and ultimately influences their purchase decision [5]. Consumers tend to make countless decisions in purchasing, and with the use of social media, their behavior is being influenced, such as their problem recognition, the search of information, evaluation of alternatives, final decision, and post-purchase decisions. Kumar et al. supported this claim; according to them, several aspects of consumer behavior are influenced by social media, knowledge collection, views, perceptions, also purchasing behavior, post-purchase interactions, and assessment [6].

This present study aims to evaluate and further analyze the influence of social media marketing on consumer buying behavior, particularly among Panabo City citizens who mostly use social media websites to purchase products and services. 
This research will use the Panabo City citizens' perception that will be able to determine how social media influences the citizens buying decision process. This research is based on a theoretical model, which is used to find out and understand the forecasted relationships among the two variables. In this manner, it may give further background about how influential and effective the social media platform as a marketing strategy that can be used by the business people to create marketing strategies based on the consumer buying behavior in order for them to achieve their desired goals most especially in increasing their sales and building a strong relationship with their customers.

\section{B. Theoretical Framework}

This study is anchored to the theory of McLuhan's Media Theory put forth by Marshall McLuhan, a Canadian philosopher and educator in 1995, the author of the famous quote "the media is the message," argued that the media itself, rather than the actual content of the media, will transform both individual behavior and the wider culture [7]. McLuhan believes that the actual messages people exchange on the new media will not be different. Our actions will be changed forever by the interactivity and frequency of new communication patterns. Thus the impact of the media on culture is much greater than the media's content. As technology becomes widely integrated with everyday life, the connection between businesses and consumers has changed a lot. After observing and recognizing the demands, preferences, purchasing behavior, and dislikes of the target market via social media, businesses develop strategies [8]. This indicates that social media has been largely adopted as an efficient tool that supports companies and businesses' marketing objectives and strategies, especially in aspects related to consumer interaction, consumer relationship management, and communication. The media themselves are instrumental in shaping human and cultural experience [1].

In 2012, a theoretical models review was conducted by Pan and Crotts to examine its relevant connection on social media towards the marketing strategies of companies in attracting their consumers [9]. Pan presented McLuhan's Media Theory and asserted that with the explosive scale of social media and its growing impact, businesses are looking for ways to make sense of and utilize this media to their benefit. Businesses can quickly test new marketing strategies and concepts online and gain instant feedback from their clients. For instance, by testing several models of consumer buying behavior, Amazon has become the biggest social science laboratory [10]. In like manner, as people on social media are revealing themselves more and more and this is done for many reasons, including their position as customers, as they search, purchase, and absorb knowledge about goods, and communicate about their experiences with others, John agrees that with the development of social media marketing, the buying behavior of the consumers is being influenced in terms of their perception and attitudes in purchasing products and services [11]. Consumers engage themselves in this kind of activity because of the advantages they have experience using social media that influences their purchasing intention [4].

Moreover, the EBK Model developed in 1968 by J.F. Engel, D.T. Kollat, and R.D. Blackwell is a theoretical framework structural models of consumer behavior with a full description of the buying decision process, reflecting the consumer behavior process during choosing a product or service [12]. Kotler's Black Box Model also presents a good illustration as it emphasizes the process as well as the factors that impact the decision making of the consumer. It is a model used in the study of consumer purchasing behavior; the model suggests that what takes place in the consumer's 'black box' of the mind of the consumer can be inferred from a study of stimuli and responses observed [13]. Voramontri and Klieb profess that if the data is gathered by the customer, he or she goes into the analysis of information, where the consumer compares the feedback to previous experiences and perceptions. After a period of reflection, consumers move to the decision-making stage, deciding to make a purchase based on logical insight. Consumers are influenced by process factors and external stimuli in the decision-making phase, including how the customer envisions him or herself after making the purchase [14].

Consumer buying behavior can sometimes be confusing and relate to many ideas and beliefs. There are various viewpoints in customer buying intention that include the 'cue utilization principle', value perspective, emotional perspective, an information processing perspective. Additional factors in buying decision process are consumer attitude and perception [11]. The correlation between social media and consumer buying behavior indicates that social media influences consumer advertising perceptions, brand attitudes, and buying intentions. It will not inherently impact the decision-making of consumers but can have a mediating effect [15]. Furthermore, social media could create brand attitudes that influence consumer behavior. The brand or product's good image will lead the customer to make a decision on their purchases. If the consumer's friend shares or suggests services or goods on their social media on social media, it affects the mindset of the brand and affects their decision-making. Author [12] highlighted that consumer buying behaviors are not simply influenced by traditional channels, but social media plays an important role in the process of consumer buying behavior, which is now heavily affected by peer reviews, social networks, blogs, etc. This proposition supports the theory of McLuhan that the media itself will change both consumer behavior and society [7]. With the research objectives in determining the influence of social media marketing, both theories are utilities in this study to further discuss the variables nature and to hold that social media marketing as the independent variable would influence and explain the dependent variable, which is the consumer buying behavior. For this research study, the buying decision process is the primary focus of behavioral patterns of consumers that 
precede, determine, and follow on the decision process for the acquisition of need satisfying products, ideas, or services.

\section{C. $\quad$ Conceptual Framework}

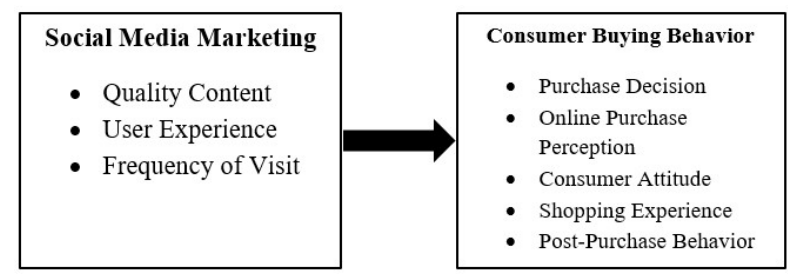

Figure 1 Conceptual Framework of the study

The diagram above illustrates the flow of the study that social media marketing correlates to consumer buying behavior. It shows the independent variable, which is Social Media Marketing, which also contains three indicators: Quality Content, User Experience, and Frequency of Visit and Exposure. As postulated by Shahid, the credibility of the influence of social media marketing can be dealt with by the three variables, which are quality of content, user experience, and frequency of visit and exposure of the consumers [16]. Meanwhile, the dependent variable of the study is the Consumer Buying Behavior, and their indicators are Purchase Decision, Online Purchase Perception, Consumer Attitude Shopping Experience, and Post-Purchase Behavior. These indicators have been shown to be highly influenced by what, when and how consumers are exposed to information via social media. It is considered as a passive process in respect of information processing [17].

\section{Research Questions}

The study intends to test the influence of Social Media Marketing on the Consumer Buying Behavior of Panabo City citizens. The study sought to answer the following questions:

R1. What is the level of Social Media Marketing in terms of:
1.1 Quality Content;
1.2 User Experience; and
1.3 Frequency of Visit?

$\mathrm{R} 2$. What is the level of Consumer Buying Behavior in terms of?

2.1 Purchase Decision;

2.2 Online Purchase Perception;

2.3 Consumer Attitude;

2.4 Shopping Experience; and

2.5 Post-Purchase Behavior?

R3. Is there a significant relationship between social media marketing and the consumer buying behavior of Panabo City citizens?

R4. Does social media marketing significantly influence the consumer buying behavior of Panabo City citizens?

\section{$1.2 \quad$ Null Hypothesis}

Hol: There is no significant relationship between social media marketing towards the consumer buying behavior of Panabo City citizens.

Ho2: Social media marketing does not significantly influence the consumer buying behavior of Panabo City citizens.

\section{METHODOLOGY}

\section{A. Research Design}

The study used a non-experimental quantitative research approach, combining correlational and regression techniques to gather information concerning social media marketing and consumer buying behavior. Non-experimental research is performed when the researcher does not have direct control of the independent variables precisely because their manifestations have already occurred. That is to say, nonexperimental research is used when it is not possible to control the variables of interest by means of manipulation, inclusion, exclusion, or group assignment [18]. Creswell defined correlation as a statistical test used to discover relationships between variables and to allow present knowledge to predict future events [19]. Similarly, regression analysis helps to test the nature of relationships between a dependent variable and one or more independent variables. Thus, the aforementioned methods were suitable in identifying the relationship between the influence of social media marketing and consumer buying behavior and how one variable influences the other.

\section{B. Research Locale}

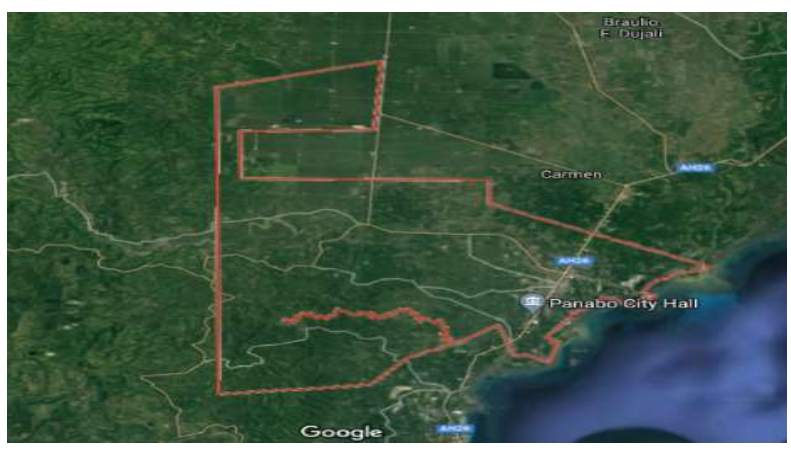

Figure 2: Research Locale

This study was conducted in Panabo City. This place is situated in Davao Del Norte, Region 11, and Philippines. Its geographical coordinates are $7^{\circ} 18^{\prime} 29^{\prime \prime}$ North, $125^{\circ} 41^{\prime} 3^{\prime \prime}$ East. The city is politically subdivided into 40 barangays. Barangay New Visayas had the biggest population of 16,566 persons in 2015 and accounted for about $8.97 \%$ of the city's population. It was followed by Barangay Gredu (Pob.) with 16,543, and the Barangay San Vicente with 14,449 persons. Barangay San Roque was the smallest barangay in 2015, in terms of population size, with 480 persons. It was followed by Barangay Katualan with 744 persons. The combined population of these three barangays accounted for about 
$25.76 \%$ percent of the population in Panabo City in 2015. With a total land area of approximately 251.23 square kilometers or 97.00 square miles, which constitutes $7.33 \%$ of Davao del Norte's total area, its population as determined by the 2015 Census was 184,599 . This represented $18.16 \%$ of the total population of Davao del Norte province or $3.77 \%$ of the overall population of the Davao Region.

\section{Participants of the Study}

The respondents of the study were the citizens who came from Panabo City, Davao del Norte. A non-probability sampling, particularly convenience sampling, was used by the researchers in selecting the respondents.

\section{D. $\quad$ Sampling Techniques}

Convenience sampling, also known as availability sampling, relies on data collection from population members who are conveniently available to participate in the study. This is where, without further criteria, the first available primary data source will be used for the analysis. No inclusion criteria defined prior to the selection of subjects include having participants anywhere researchers can find them [20]. During this time of pandemic crisis, convenience sampling is suitable for this study. Thus, the researchers have chosen respondents who are willing to be part of the study and can access the Internet and as long as he/she is a citizen from Panabo City. To measure the population and sample in the study, Slovin's formula was used, $\mathrm{n}=$ Total sample, $\mathrm{N}=$ Population, and $\mathrm{e}=$ Margin of error. The formula is $\mathrm{n}=\frac{\mathrm{N}}{1+\mathrm{Ne}^{2}}$ [23].

Using Slovin's formula, there are 399 total number respondents from the city who are engaging their selves in utilizing social media as a market place medium of product and services resources. As cited by Delice, the researcher should decide on an appropriate size for the sample depending on the research topic, population, aim of the research, analysis techniques, and sample size in similar research, the number of the subgroups in the sample, population variability, and research design. Accordingly, a sample size between 30 and 500 at a $5 \%$ confidence level is generally sufficient for many researchers [25]. Thus, these numbers of respondents are essential to identify credible data about the relationship between social media marketing and consumer buying behavior.

\section{E. Statistical Treatments}

All data are gathered, tallied, encoded, and interpreted using MS Excel 2016 and IBM SPSS (Statistical Package for the Social Sciences), a free and open-source graphical program for statistical analysis supported by the University of Amsterdam. The data that was collected from this study are subjected to statistical treatments. This study utilized mean average, Pearson r, and Regression Analysis to answer each of the laid study questions to the corresponding data collected and the problem mentioned. Pearson $\mathrm{r}$ was used for it is recognized as the best way to calculate the relation between variables. It offers information on the magnitude of the correlation of the association, as well as the nature of the twovariable relationship. Moreover, Regression Analysis was also utilized. It is a set of statistical techniques used to estimate the relationships between one or more independent variables and a dependent variable. It can be used to determine the strength of the relationship between variables and model the relationship between them in the future. Multiple linear regression (MLR) was used. It is a statistical technique that uses several explanatory variables to predict the outcome of a response variable. The goal of multiple linear regressions (MLR) is to model the linear relationship between the explanatory (independent) variables and response (dependent) variable.

\section{F. Data Collection Procedure}

Data were gathered through the use of an online survey questionnaire with the aid of Google Forms. The researchers used a standard questionnaire to have an efficient questionnaire that helped assess social media marketing and consumer buying behavior. An online survey has the growing popularity since it was widely used, is a systematic approach of gathering data to the targeted audience that can complete the survey questions over the Internet [21]. On the other hand, Google Forms is a popular product in online survey research. It is a cloud-based platform for data processing used for webbased questionnaire design and creation offered by Google Inc. [22]. In carrying out the online survey of the study, the researchers first asked for the approval of the respondents. The researchers disseminated questionnaires by sending and sharing the link of an online survey questionnaire to the possible respondents of Panabo City. After the dissemination of the questionnaire, the data was gathered through answered online, tallied, and subjected to statistical interpretation using appropriate statistical tools.

\section{G. Research Instrument}

Primary data was used in the study in which the researchers disseminated the standardized questionnaire to the respondents online. In gathering data for social media marketing, the questionnaire was based on the Effectiveness of Social Media by Hasan Shahid. The said study was conducted at the North-South University of Dakha, Bangladesh, which aims to realize the possibilities, leverage the opportunity and reserve the perceived value of consumers, and evaluate how the Internet affects the costume in buying the product and the study result show that effectiveness and influence of social media marketing are positively correlated with consumer buying behavior, and quality of content, user experience, and frequency of visit have a positive influence on consumer purchase intention [16]. Additionally, in measuring consumer buying behavior, researchers created modified questionnaires based on different studies concerning consumer buying behavior. In relation to this, Sandhusen [23] claimed that consumer behavior might be classified using the Black Box Model, which includes environmental factors, 
buyer's black box (consumer's mind), and buyer's response. In the model, the whole process of decision making is explained that marketing stimuli and environmental elements affect buyer's characteristics (Attitude, Perception, and Knowledge) and decision-making process (Purchase Decision and PostPurchase Behavior), then the buyer's response is obtained. In answering the questionnaire, the respondents will evaluate their answers based on the point 5 Likert Scale. The mean of the indicators will be interpreted based on the range of means, descriptive rating, and interpretation.

Table I: Scale for Social Media Marketing

\begin{tabular}{|c|c|c|l|}
\hline Scaling & Range of Means & Descriptive Rating & Descriptive Interpretation \\
\hline 1 & $1.00-1.79$ & Very Low & $\begin{array}{l}\text { This means that social media } \\
\text { marketing is never observed }\end{array}$ \\
\hline 2 & $1.80-2.59$ & Low & $\begin{array}{l}\text { This means that social media } \\
\text { marketing is rarely observed }\end{array}$ \\
\hline 3 & $2.60-3.39$ & Moderately High & $\begin{array}{l}\text { This means that social media } \\
\text { marketing is sometimes } \\
\text { observed }\end{array}$ \\
\hline 4 & $3.40-4.19$ & High & $\begin{array}{l}\text { This mans that social media } \\
\text { marketing is often observed }\end{array}$ \\
\hline 5 & $4.20-5.00$ & Very High & $\begin{array}{l}\text { This means that social media } \\
\text { marketing is always } \\
\text { observed }\end{array}$ \\
\hline
\end{tabular}

Table II: Scale for Consumer Buying Behavior

\begin{tabular}{|c|c|c|l|}
\hline Scaling & Range of Means & Descriptive Rating & Descriptive Interpretation \\
\hline 1 & $1.00-1.79$ & Very Low & $\begin{array}{l}\text { This means that buying } \\
\text { behavior of the consumer is } \\
\text { never observed }\end{array}$ \\
\hline 2 & $1.80-2.59$ & Low & $\begin{array}{l}\text { This means that buying } \\
\text { behavior of the consumer is } \\
\text { rarely observed }\end{array}$ \\
\hline 3 & $2.60-3.39$ & Moderately High & $\begin{array}{l}\text { This means that buying } \\
\text { behavior of the consumer is } \\
\text { sometimes observed }\end{array}$ \\
\hline 4 & $3.40-4.19$ & High & $\begin{array}{l}\text { This means that buying } \\
\text { behavior of the consumer is } \\
\text { often observed }\end{array}$ \\
\hline 5 & $4.20-5.00$ & Very High & $\begin{array}{l}\text { This means that buying } \\
\text { behavior of the consumer is } \\
\text { always observed }\end{array}$ \\
\hline
\end{tabular}

\section{H. Ethical Considerations}

For research projects, ethical considerations are important since all respondents have moral and legal rights. For this study, the researcher ensured the protection of individuals with the aid of informed consent that without their permission, they did not violate their privacy, that the research did not harm their feelings and that all the information received from them was recognized and accurately represented. Respondents are not forced to respond and review the questionnaires in the survey carried outvoluntary participation by connecting online. Using online platforms (google form), the researchers first explained the intent and objective of the study before leasing them to participate in or participate in the investigation, especially in subsidizing the information framework of the research. All of the details and directions were clearly indicated on the platforms of Google. Respondent's decision will be valued and respected. Some ethical considerations this study insured for the participants was:

Privacy and Confidentiality: Guaranteeing that information provided will be unidentifiable by anybody other than by the researcher. Ensuring they were knowledgeable that if any of the information resulting from the research is to be used for presentations or reports, all identifying information will be changed to maintain privacy and confidentiality. Confirming that they were well-informed that the results will be presented in the thesis and they will be seen by the researcher's supervisor, a second marker, and the external examiner. Ensuring that they understood that the thesis may be read by future students on the course and may be published in a research journal, but anyone reading this thesis won't know who they are.

Safety: Eliminating any risk elements ensuring safety will be consistent over time. I am confirming that the research is not harmful to respondents and certifies proper use of information.

Autonomy: The researcher ensured that the respondent's contribution is completely voluntary and that they may withdraw from the research at any time. From here, there will be no further collection or analysis of data, and all existing data will be removed. Any unreturned questionnaires and any mothers who refuse to take part in the project will be counted in the research.

Dignity: All respondents had the freedom to make their own fully informed decisions. All participants were treated with great respect.

Informed consent: Each participant received a consent letter explaining some of the key elements of this study and what is expected of them as the respondent and the researcher. A consent form was also supplied with the letter which respondents signed if they agree to take part and understood their respondent in the research.

\section{RESULTS AND DISCUSSIONS}

The gathered data has been carefully analyzed and interpreted. Results and discussion of findings on social media marketing and consumer buying behavior are presented below.

\section{Level of Social Media Marketing}

Table 3 shows the collected results to what is the Level of Social Media Marketing in terms of quality content, User Experience, and Frequent Visit. The mean level of quality content of the respondents is 3.92 with a standard deviation of 0.50 . This shows that the quality content of the respondents is high. With another interpretation of the mean result that is 3.92 , it also implies that, in terms of quality content, social media marketing is often observed by the consumer. Meanwhile, the mean level of experience of the respondents is 3.70 with a standard deviation of 0.70 . This implies that the experience of the respondents is high, also the mean indicates 
that social media marketing is often observed. On the other hand, the frequency of visit as an indicator has the mean level of 3.90 with a standard deviation of 0.52 . This indicates that the frequency of visits of the respondents is high and that social media marketing is often observed by the consumer. Additionally, the mean level of social media marketing of the respondents is 3.84 with a standard deviation of 0.42 . This shows that the level of social media marketing of the respondents is high.

Results revealed that the level of social media marketing in Panabo City is high, implying that it is often observed by the consumer. This shows that consumers are highly immersed to the benefits brought by the social media marketing which draws their attention and encourages them to connect, share and interact in order to meet their needs [4]. Moreover, Shahid [17] professed that the indicators quality content and frequency of visit on social media marketing shown to be part of building the trust, loyalty, and discovery of behavioral trends of the consumer.

\begin{tabular}{lccccc}
\multicolumn{5}{c}{ Table III: Level of Social Media Marketing } \\
Descriptive Statistics
\end{tabular}

Level of Consumer Buying Behavior

Shown in Table 4 are the collected results to what is the Consumer Buying Behavior in terms of Purchase Decision, Online Purchase Perception, Consumer Attitude, Shopping Experience, and Post-Purchase Behavior. The mean level of purchase decision of the respondents is 3.90 with a standard deviation of 0.51 . This shows that the level of purchase decision of the respondents is high. Result also interprets that respondents' consumer buying behavior with this indicator is is often observed. The mean level of online purchase perception of the respondents is 3.92 with a standard deviation of 0.44 . This shows that the level of online purchase perception of the respondents is high, implying that consumer buying behavior is often observed. Moreover, the mean level of consumer attitude of the respondents is 3.83 with a standard deviation of 0.51 . This shows that the level of consumer attitude of the respondents is high, suggesting that consumer buying behavior is often observed. The shopping experience of the respondents has mean level of 3.84 with a standard deviation of 0.51 . This shows that the level of shopping experience of the respondents is high which indicates that this buying behavior of the consumer is often observed. The means level of post-purchase behavior of the respondents is 3.89 with a standard deviation of 0.62 . This shows that the level of post-purchase behavior of the respondents is high, reveals that buying behavior of the consumer is often observed.

Overall, the mean level of consumer buying behavior of the respondents is 3.88 with a standard deviation of 0.36 . This shows that the level of consumer buying behavior of the respondents is high, indicating that the respondent's buying behavior as a consumer is often observed. Hence, it implies that consumer buying behavior are subdivided to different aspects that would further analyze and understand the nature of consumer's purchasing behavior [16]. The findings would also a big help for the marketers in assessing the needs, wants and likes of consumers and to consider what their competition could look like [4]. Further, the highest-rated indicators of consumer buying behavior are purchase perception and online purchase perception, with a descriptive level of high. This result suggests that consumers believed that their buying behavior is tested in making purchase decision and even via online. As expressed by Sandhusen, the whole process of decision making is explained that marketing stimuli and environmental elements affect consumer characteristics in selecting information and comparing their purchase decisions [23].

Table IV: Level of Consumer Buying Behavior

\begin{tabular}{lccccc}
\hline \multicolumn{6}{c}{ Descriptive Statistics } \\
\hline PD & N & Minimum & Maximum & Mean & Std. Deviation \\
OPP & 399 & 1.00 & 5.00 & 3.90 & .51 \\
CA & 399 & 1.38 & 5.00 & 3.92 & .44 \\
SE & 399 & 1.33 & 5.00 & 3.83 & .51 \\
PPB & 399 & 1.00 & 5.00 & 3.84 & .51 \\
CBB & 399 & 2.00 & 5.00 & 3.89 & .62 \\
Valid N (listwise) & 399 & & 4.54 & 3.88 & .36 \\
\hline
\end{tabular}

Significance of the Relationship between Social Media Marketing and the Consumer Buying Behavior

Presented in the Table 5 the significance of the relationship between social media marketing and consumer buying behavior with overall computed r-value of 0.571 which means that there is a MODERATE positive relationship in the learnability of social media marketing and consumer buying behavior of the respondents. Thus, we reject the null hypothesis since $p$-value is $0.000<0.05$. There is a significant relationship in the learnability of social media marketing and consumer buying behavior of the respondents. Furthermore, it is shown that association between user experience and consumer attitude has the highest r-value of 0.445 which means that there is a MODERATE positive relationship in the user experience and consumer attitude of the respondents. However, online purchase decision and user experience relationship got the lowest $r$-value of 0.160 which means that 
there is a VERY WEAK positive relationship in the user experience and post-purchase behavior of the respondents.

It is revealed in the correlational analysis that there is a significant relationship between the social media marketing and consumer buying behavior. Particularly the relationship between the user experience and consumer attitude with a positive, moderate, and significant correlation. This results confirms the proposition of Voramontri and Klieb that the consumer compares the feedback to previous experiences and perceptions and after a period of reflection, consumers move to the decision-making stage, deciding to make a purchase based on logical insight [14].

Table V: Significance of the Relationship between Social Media Marketing and the Consumer Buying Behavior

\begin{tabular}{|c|c|c|c|c|c|c|}
\hline \multirow[b]{2}{*}{$\begin{array}{l}\text { Social Media } \\
\text { Marketing }\end{array}$} & \multicolumn{6}{|c|}{ Consumer Buying Behavior } \\
\hline & $\begin{array}{l}\text { Purchase } \\
\text { Decision }\end{array}$ & $\begin{array}{l}\text { Online } \\
\text { Purchase } \\
\text { Decision }\end{array}$ & $\begin{array}{l}\text { Consumer } \\
\text { Attitude }\end{array}$ & $\begin{array}{l}\text { Shopping } \\
\text { Experience }\end{array}$ & $\begin{array}{l}\text { Post- } \\
\text { Purchase } \\
\text { Behavior }\end{array}$ & Overall \\
\hline $\begin{array}{l}\text { Quality } \\
\text { Content }\end{array}$ & $\begin{array}{c}.304 \\
(.000)\end{array}$ & $\begin{array}{c}.371 \\
(.000)\end{array}$ & $\begin{array}{c}.369 \\
(.000)\end{array}$ & $\begin{array}{c}.323 \\
(.000)\end{array}$ & $\begin{array}{c}.217 \\
(.000)\end{array}$ & $\begin{array}{c}.451 \\
(.000)\end{array}$ \\
\hline $\begin{array}{c}\text { User } \\
\text { Experience } \\
\text { Frequency } \\
\text { of Visit }\end{array}$ & $\begin{array}{c}.181 \\
(.000) \\
.378 \\
(.000)\end{array}$ & $\begin{array}{l}.160 \\
(.000) \\
.375 \\
(.000)\end{array}$ & $\begin{array}{c}.445 \\
(.000) \\
.350 \\
(.000)\end{array}$ & $\begin{array}{c}.239 \\
(.000) \\
.329 \\
(.000)\end{array}$ & $\begin{array}{l}.205 \\
(.000) \\
.216 \\
(.000)\end{array}$ & $\begin{array}{l}.357 \\
(.000) \\
.469 \\
(.000)\end{array}$ \\
\hline Overall & $\begin{array}{c}.377 \\
(.000)\end{array}$ & $\begin{array}{c}.391 \\
(.000)\end{array}$ & $\begin{array}{c}.539 \\
(.000)\end{array}$ & $\begin{array}{c}397 \\
(.000)\end{array}$ & $\begin{array}{c}.289 \\
(.000)\end{array}$ & $\begin{array}{c}.571 \\
(.000)\end{array}$ \\
\hline
\end{tabular}

Significance of the Influence of Social Media Marketing towards Consumer Buying Behavior of Panabo City

Revealed in Table 6 is the significance of the influence of social media marketing towards consumer buying behavior of Panabo City with a computed r-value of .595, r-squared value of .354, and p-value of .000 lower than .05 level of significance. Hence, with the overall result rejection of the null hypothesis is applied in this context. It is presented that all of the social media marketing indicators got p-values lower than the required level of significance which is .05 . Also, using stepwise regression, it has found out that among the indicators of social media marketing, all are predictors of the consumer buying behavior. The prediction is illustrated by the equation $\mathrm{y}=0.217 \mathrm{x}_{1}+0.234 \mathrm{x}_{2}+0.085 \mathrm{x}_{3}+1.803$, with a low predictive power of $35.4 \%$.

Table VI: Significance of the Influence of Social Media Marketing towards Consumer Buying Behavior of Panabo City

\begin{tabular}{|c|c|c|c|c|c|c|}
\hline \multicolumn{7}{|c|}{ Coefficients $^{a}$} \\
\hline & \multirow{3}{*}{ Model } & \multirow{2}{*}{\multicolumn{2}{|c|}{$\begin{array}{l}\text { Unstandardized } \\
\text { Coefficients }\end{array}$}} & \multirow{3}{*}{$\begin{array}{l}\text { Standardized } \\
\text { Coefficients } \\
\text { Beta }\end{array}$} & \multirow{3}{*}{$t$} & \multirow{3}{*}{ Sig. } \\
\hline & & & & & & \\
\hline & & B & Std. Error & & & \\
\hline \multirow{7}{*}{3} & (Constant) & 1.803 & .142 & & 12.665 & .000 \\
\hline & FV & .217 & .031 & .315 & 7.042 & .000 \\
\hline & QC & .234 & .030 & .327 & 7.706 & .000 \\
\hline & UE & .085 & .022 & .166 & 3.778 & .000 \\
\hline & & $R=.595^{b}$ & & & & \\
\hline & & $R^{2}=.354$ & & & & \\
\hline & & $\mathrm{P}=.000$ & & & & \\
\hline
\end{tabular}

Moreover, it is observed in the regression analysis that there is an $r$ squared value of .354 . This means that 35.4 percent of the variance of the consumer buying behavior can be attributed to the variance of the social media marketing. While the remaining 64.6 percent are variance that might occur to the consumer buying behavior not covered in this study.

Thus, this illustrates that there is a significant influence between the two variables and all indicators of the social media marketing influence the consumer buying behavior of the citizen of the Panabo City. As presented by the McLuhan's Media Theory, social media as an effective tool of marketing has been greatly influence the consumer buying behavior [7]

Agreed by [11] the development of social media marketing, the buying behavior of the consumers is being influenced in terms of their perception and attitudes in purchasing products and services. Consumers engage themselves in this kind of activity because of the advantages they have experience using social media that influences their purchasing intention. Additionally, the EBK Model believed that consumers are influenced by process factors such as how social media influence their views and external stimuli in the decisionmaking phase, including how the customer envisions him or herself after making the purchase [13].

A related influence between social media marketing and consumer buying behaviour has been presented by Asma and Misbah, showing that SMM is an effective marketing tool that affects customer perception and ultimately affects their buying decision [5]. Consumers appear to make numerous buying decisions and their behavior is impacted by the use of social media, such as their issue identification, knowledge quest, alternative assessment, final decision, and postpurchase decisions. According to Kumar et al., many aspects of consumer behavior are affected by social media, the aggregation of information, views, expectations, buying behavior, post-purchase behaviors, and evaluation [6].

\section{CONCLUSIONS AND RECOMMENDATIONS}

Social media marketing in Panabo City is high, implying that it is often observed by the consumer. Therefore, social media marketing predictors such as its quality content, user experience, and frequency of visit is often observed by the citizens who engage in online buying. As a result, social media is shown to be an effective marketing strategy that helps the consumer to gain their specific needs, and it develops consumer trust, loyalty, and discovery to the modern world.

Consumer buying behavior in Panabo City is high, indicating that the respondent's buying behavior as a consumer is often observed. As a consumer their purchasing behavior, online and post-buying behavior, attitude, and shopping experiences is being often observed, they believed that this process would meet their impulse, needs, demands, wants, necessity, and lifestyle. Further, purchasing behavior and online purchasing 
behavior rated high. Thus, consumers are highly engaged with these buying behaviors.

There is a positive, moderate, and significant correlation between social media marketing and consumer buying behavior. Additionally, there is a moderate positive relationship in the user experience and consumer attitude, hence, consumer compares their feedback to their previous experiences and perceptions and after a period of reflection their attitude as a consumer is being affected. On the other hand, online purchase decision and user experience show to have a very weak relationship.

Furthermore, regression analysis result revealed that social media marketing significantly influences consumer buying behavior. Anchored to the McLuhan's Media Theory, social media is indeed an effective tool of marketing that has been greatly influencing consumer buying behavior [7]. Thus, in this manner, consumers are influenced by process factors and external stimuli brought by the social media marketing in the decision-making phase, including how the consumer envisions him or herself after making the purchase, as to what the EBK Model also emphasizes [13]. Hence, this result is of good use in order to understand how consumers will respond these heightened avenues of communication.

Based on the findings of the study, it is recommended for the consumers since social media marketing drive the process of conducting online businesses to assess the experiences they have encountered in engaging marketing through the use of social media, such as the integrity and quality of information of the social media they are using. Also, it is recommended to the business owners, specifically for those sellers/producers who use social media as their medium of the market, to improve their marketing strategy that would gain a number of consumers and to develop a sense of belongingness and trust, a comfortable environment in the virtual world. Furthermore, it is recommended for future researchers to conduct a study that would investigate the effectiveness of social media marketing in this new normal considering the other predictors of consumer buying behavior as it shows to have a wide range of scope in understanding the purchase behavior of the people.

\section{ACKNOWLEDGEMENT}

We, the researchers from Davao Del Norte state college taking up a Bachelor of Science in Information Technology. We wish to show our appreciation to our Quantitative Methods Instructor and the new dean of the Institute of Computing Professor Mark Van M. Buladaco for exerting extra efforts in sharing his knowledge and wisdom in research despite this pandemic. We would like to thank our research adviser Professor Ronel G. Dagohoy for the guidance and advice he shared with us throughout this research journey. The assistance provided by Professor Ellvan M. Campos as our statistician was greatly appreciated. To the contributor's and other members of this group Janelle Joy A. Franco, Jesie I. Escoton, and Carlo T. Banac whom we work together as a team to create reviews, discussions and learning to communicate and work online and most specially, in knowing each other's strengths and weaknesses in order to $d$ the amount of work, this will not be possible without your support and contribution to this research. To our parents who keep on supporting us financially and mentally. Above all, to our Almighty God for giving us wisdom, knowledge, and determination for succeeding in this study.

\section{REFERENCES}

[1] Peighambari, K., Sattari, S., Kordestani, A., \& Oghazi, P. (2016). Consumer Behavior Research: A Synthesis of the Recent Literature. SAGE Open. https://doi.org/10.1177/21582440166456 38 [Retrieved: Jan 03 2021]

[2] Team, D. J. (2020). The Importance of Consumer Behavior in Marketing. [Online]. Available: https://www.demandjump.com /blog/the-importance-of-consumer-behavior-in-marketing. [Retrieved: 09-Jan-2021].

[3] Ramirez, V. (2019). Contemporary Issues in Consumer Behavior," [Online]. Available: https://bizfluent.com/list-7780107contemporar y-issues-consumer-behavior.html. [Retrieved: 09Jan-2021].

[4] Perumal, P. \& Yoganathen, A. (2018). (Pdf) Influence of Social Media Marketing on Consumer Buying Decision Making Process," ResearchGate, [Online]. Available:https://www.res earchgate.net/publiccation/326294733_INFLUENCE_OF_SOCIA L_MEDIA_MARKETING_ON_CONSUMER_BUYING_DECIS ION MAKING PROCESS. [Retrieved: 09-Jan-2021].

[5] Asma, G. \& Misbah, M. (2018). Impact of Social Media Marketing on Consumer Buying Behaviour - A study," Zenodo, [Online]. Available: http://doi.org/10.5281/zenodo.1285933. [Retrieved: 09-Jan-2021].

[6] Kumar, A., Bezawada, R., Rishika, R., Jana kiraman, R., \& Kannan,P. K. (2016). From social to sale: The effects of firm generated content in social media on consumer behavior. Journal $\begin{array}{lllll}\text { of } & \text { Marketing, } & 80(1), & 7 & -\end{array}$ https://zenodo.org/record/1285933\#.X88OZ9gzbMU [Retrieved: 09-Jan-2021].

[7] McLuhan, M. (1995) Understanding media: the extensions of man. Cambridge (Mass.): The MIT Press, 2013. https://doi.org/10.1177/2158244016645638 [Retrieved: Jan 03 2021]

[8] Khanna, U. (2016). Social media impact on advertising," тм "Social media impact on advertising" Keyword Found Websites Listing | Keyword Suggestions. [Online]. Available: https://www.keyword-suggest-

tool.com/search/social+media+impact+on+advertising/. [Retrieved: 09-Jan-2021].

[9] Pan, B., \& Crotts, J. (2012). Theoretical models of social media, marketing implications, and future research directions. https://www.researchgate.net/publication/254862367_Theoretical_ models_of_social_media_with_marketing_implications. [Retrieved: 09-Jan-2021].

[10] Sigala, M., Christou, E., \& Gretzel, U. (2012). Social Media in Travel, Tourism and Hospitality: Theory, Practice and Cases (pp. 73-86). Surrey, UK: Ashgate. ResearchGate. [Online]. Available: https://www.researchgate.net/publication/254862367_Theoretical_ models of social media with marketing implications. [Retrieved: 09-Jan-2021].

[11] Contractor, N. (2009). The Emergence of Multidimensional Networks. Journal of Computer-Mediated Communication, 14(3), 743-747. doi:10.1111/j.1083-6101.2009.01465.x [Retrieved: Jan 03 2021] 
[12] Engel J.F., Kollat D.T., Blackwell R.D. (1968). "Free Consumer Behaviour Literature Review," The WritePass Journal, 09-Jul2013. [Online]. Available: https://writepass.com/journal/2011/10/free-consumer-behaviourliterature-review/. [Retrieved: 09-Jan-2021].

[13] Kotler, P., Armstrong, G., Saunders, J., Wong, V., (2004) Consumer Behaviour, 5th edition, USA: Prentice Hall.: https://www.researchgate.net/publication/269079357_Consumer_ Behaviour_And_Values_Driving_Organic_Food_Choice_In_Lat via_A_Means-End_Chain_Approach [Retrieved: Jan 03 2021].

[14] Voramontri, D. \& Klieb, L. (2018). Impact of Social Media on Consumer Behaviour. Retrieved January 09, 2021, from https://www.researchgate.net/p ublication/326098250_Impact_of_Social_Media_on_Consumer_B ehaviour

[15] Ohio University (2020). 4 Consumer Behavior Theories Marketers Should Know. (2020). Retrieved January 09, 2021, from https://onlinemasters.ohio.edu/blog/four-consumer-behaviortheories-every-marketer-should-know/

[16] [Shahid, H. (2019). (PDF) Effectiveness of Social media marketing. Retrieved January 09, 2021, from https://www.researchgate.net/p ublication/335714818_Effectiveness_of_Social_media_marketing

[17] Dhyani, S. (2018). A Study on Impact of Social Media on Cosumer Buying Behavior. G.L. Bajaj Institute of Management and Research APlot No.2, Knowledge Park-III https://www.slideshare.net/MdAktar1/impacts-of-social-media-onconsumer-behavior

[18] Edmonds, W. Alex and Thomas D. Kennedy. "Quantitative Methods for Nonexperimental Research." An Applied Guide to Research Designs: Quantitative, Qualitative, and Mixed Methods.Seconded Thousand Oaks: SAGE Publications, Inc,
2017, pp. 117-119. SAGE Research Methods. 17 Dec 2020, doi: http://www.doi.org/10.4135/9781071802779.

[19] Creswell J. (2012). Educational Research: Planning, Conducting, and Evaluating Qualitative and Quantitative Research, 4th Ed. Toronto: Pearsonhttps://douglasfleming.weebly.com/uploads/1/3/0 /5/1305380/correlation_research_design_presentation_kieran_and emmanuel.pdf. Retrieved January 09, 2021, from http://www.doi.org/10.4135/9781071802779

[20] Dudovskiy, J (2011). Convenience Sampling. Business Research Methodology. Homepage - Research-Methodology Retrieved January 09, 2021, from https://research-methodology.net/

[21] Evans, J. R., \& Mathur, A. (2005). The value of online surveys. Internet Research, 15(2), 195-219. doi:10.1108/106622405 10590360 [Retrieved: Jan 03 2021]

[22] Vasantha Raju N., \& Harinarayana, N.S. (2016). Online survey tools: A case study of Google Forms. Paper presented at the National Conference on "Scientific, Computational \& Information Research Trends in Engineering, GSSS-IETW, Mysore. https://www.researchgate.net/publication/326831738_Online_surv ey_tools_A_case_study_of_Google_Forms [Retrieved: Jan 03 2021].

[23] Sandhusen, R. L. (2000). Marketing (3rd ed.). New York, NY: Barron's Business Review Books. An Empirical Study of Factors Influencing Consumer Behavior in Electric Appliances Market. Available from: https://www.researchgate.net/publication/23590 1579_An_Empirical_Study_of_Factors_Influencing_Consumer_B ehavior_in_Electric_Appliances_Market [Retrieved: Jan 03 2021].

[24] Almeda, J., T. Capistrano, G. and Sarte, (2010). On the Misuse of Slovin's Formula. Retrieved from www.psai.ph on July 29, 2017. [Retrieved: Jan 03 2021].

[25] Delice, A. (2010). The Sampling Issues in Quantitative Research. https://files.eric.ed.gov/fulltext/EJ919871.pdf [Retrieved: Jan 03 2021]. 